\title{
Para uma historiografia do operariado de Alagoas
}

\author{
For a historiography of the Alagoas working class
}

Ivo dos Santos Farias*

\begin{abstract}
Resumo
O seguinte artigo busca apresentar um panorama sobre a construção historiográfica a respeito do operariado alagoano, compreendida entre fins da década de 1980 e a atualidade. Para isso, indica a produção acadêmica de três diferentes gerações de estudiosos, bem como o perfil de cada uma delas, sinalizando os avanços nas pesquisas e continuidades entre as gerações. Além disso, discorre sobre números que identificam significativo crescimento de produção nesta temática, comparando-a inclusive com outras regiões do país. Destaca também a importância da produção fílmica e documental sobre o operariado em Alagoas. Compreende, por fim, que estes estudos têm contribuído para desmistificar uma perspectiva presente ainda no imaginário coletivo que entende Alagoas apenas como espaço construído historicamente sobre o grande latifúndio, na medida em que aponta para a existência de experiências fabris e trajetórias políticas conectadas com o processo de modernização brasileira ao longo do século $\mathrm{XX}$.
\end{abstract}

Palavras-chave: Historiografia; Operariado; Alagoas.

\begin{abstract}
The following article seeks to present an overview about the historiographical construction of alagoan workers, between the late 1990s and the presente day. To do this, it indicates the academic production of three different generations of scholars, as well as the profile of each of them, signaling advances in research and continuities between generations. In addition, it discusses numbers that identify significant production growth in this area, comparing it with other regions on the workforce in Alagoas. Finally, it understands that these studies have contributed to demystify a present perspective still in the collective imaginary that Alagoas understands only a historically constructed space on the large latifudio, since in that it points to the existence of factory experiences and political trajectories connected with the process of modernization throughout the $20^{\text {th }}$ century.
\end{abstract}

Key words: Historiography; Working class; Alagoas.

\section{Introdução}

Em meados dos anos de 1990, a historiadora Sílvia Regina Ferraz Petersen defendeu que os estudos sobre o movimento operário no Brasil, geralmente, eram feitos em vista de pouquíssimas menções a regiões que não fossem o eixo Rio-São Paulo e que tal predominância estava ligada ao fato de aquele ser o espaço de maior

\footnotetext{
" Historiador e Doutor em Ciências Sociais pela Universidade Estadual Paulista Júlio de Mesquita Filho (UNESP/Marília).
} 
concentração industrial no país. A autora seguiu afirmando que o perigo de tal centralização seria o de gerar equívocos sobre as diferentes experiências operárias nas diversas regiões do país, pois contribuía para que houvesse

[...] uma tendência dos autores estenderem ao "Brasil" o que na verdade correspondeu ao centro do país. Em outras palavras, o que era também um estudo regional (embora indubitavelmente da região política e economicamente hegemônica) ganhou uma dimensão nacional ou global. Rio de Janeiro e São Paulo foram constituídos como "centros definidores de sentido" para a história operária do Brasil (PETERSEN, 2009, p. 130).

Daí, embora o eixo Rio-São Paulo desempenhe o papel hegemônico desde o início do século $\mathrm{XX}^{1}$, isso não justifica a pequena quantidade de estudos em outras regiões, mas abre portas para novas investigações a fim de se compreender o porquê de seu acanhamento historiográfico, pois não se pode ignorar que outros espaços também tiveram experiências - apesar de proporcionalmente mais discretas - para com a economia e as relações fabris.

Assim sendo, o estudo e propagação das particularidades das regiões periféricas podem colaborar para a compreensão da complexidade da formação social brasileira, porque, a partir do conhecimento de outras experiências fabris, enxerga-se tramas e problemáticas, até então, não pensadas do ponto de vista do eixo dominante ${ }^{2}$. Além disso, esses estudos servem para ampliar a análise sobre a formação social das regiões estudadas.

Segundo a hipótese da historiadora Sílvia Petersen,

[...] a investigação sobre a história operária no Brasil poderia ocupar um patamar nacionalmente mais representativo se houvesse o diálogo mais efetivo entre a bem conhecida e abundante historiografia referente ao eixo central dessa história (Rio de Janeiro e São Paulo) e a que aborda o tema nos demais estados e mesmo no exterior (PETERSEN, 2009, p. 1).

Com base nessas considerações, após duas décadas da inquietação de Petersen, percebe-se um notável crescimento de pesquisas sobre o operariado em diversas regiões

\footnotetext{
${ }^{1}$ Até fins do século XIX, a indústria brasileira estava descentralizada, pois "das 45 fábricas de tecidos existentes em 1882, 12 localizavam-se na Bahia, 11 no Rio de Janeiro, 9 em São Paulo e 8 em Minas Gerais" (HARDMAN; LEONARDI, 1982, p. 34). São Paulo só veio a ter um salto de sua capacidade produtiva a partir da década de 1920 (CANO, 1985). Em Alagoas, a primeira indústria têxtil foi fundada em 1857, no então povoado denominado Fernão Velho, às margens da lagoa Mundaú. Na última década do século XIX, foram fundadas mais quatro fábricas, além de mais outras sete nas primeiras décadas do século XX, totalizando-se doze indústrias têxteis (FARIAS, 2014).

${ }^{2}$ Como o objeto de estudo aqui apresentado está em Alagoas, ou seja, territorialmente o segundo menor estado da região Nordeste (e do Brasil), o foco da compreensão sobre a produção bibliográfica está no Nordeste. Não se adentrará, portanto, nas minúcias das demais regiões brasileiras.
} 
do país (principalmente após a década de 2010), o que pode ser explicado pela ampliação de cursos de pós-graduação, pela percepção mais clara de um processo de desmonte fabril nas regiões de produção industrial tradicional ${ }^{3}$ (com auge entre as décadas de 1930 a 1960 e decadência a partir da década de 1980) e pela possibilidade de acesso a acervos e fontes documentais ${ }^{4}$. Ainda assim, pode-se considerar tímido o montante de produção em regiões fora do eixo Rio-São Paulo até então, tal como será apresentado mais adiante, com base nas pesquisas realizadas por Petersen.

Tendo em vista esses pressupostos, este artigo propõe apresentar um levantamento sobre a recente construção historiográfica do operariado de Alagoas, a partir da percepção de um significativo crescimento nas pesquisas sobre esta temática, principalmente durante a década de 2010, ou seja, apenas dois decênios após seus primeiros ensaios, realizados em fins da década de 1980, tal como será apontado ao longo do texto.

De algum modo, esses estudos têm servido como contraposição ao imaginário exclusivamente rural-coronelístico-canavieiro na região, pois apresenta outras problemáticas que lançam luz para se compreender diferentes dimensões de sua formação histórico-social e podem servir como meio para desnaturalizar as relações político-sociais vigentes na atualidade. Essa leva de estudos tem contribuído, desse modo, para problematizar questões importantes para a reconstrução do passado e do presente alagoano, na medida em que trazem à tona o protagonismo dos/as trabalhadores/as urbanos/as em suas diversas formas de atuação política, intercambiadas em muitos casos pelo anarquismo, socialismo e comunismo e/ou por suas lutas trabalhistas e sindicais.

Assim sendo, este artigo está divido em quatro momentos, sendo o primeiro um levantamento estatístico sobre a produção historiográfica referente ao operariado, situando Alagoas nesses números; em seguida, as dificuldades e avanços da produção no estado, tendo o parâmetro a produção intelectual canavieira; a produção fílmica (iniciada anterior à produção escrita); e, por fim, as três diferentes gerações de estudos sobre o operariado em Alagoas.

\footnotetext{
${ }^{3}$ Detalhe interessante é que uma parcela dos mais novos pesquisadores sobre esta temática é composta por filhos de famílias residentes em vilas operárias, o que lhes contribuiu uma percepção mais evidente sobre o processo de desmonte fabril, bem como a necessidade de se compreender tal decurso e suas consequências.

${ }^{4}$ Lança-se, aqui, a hipótese de que a partir do golpe de 2016 no país, inicie-se um retrocesso nas produções historiográficas devido aos cortes em verbas para pesquisas.
} 


\section{Números da produção historiográfica sobre o operariado: o lugar de Alagoas}

De acordo com o levantamento bibliográfico de Petersen (2009), foi possível constatar que, além das exposições de dois artigos publicados na década de 1940, no estado da Bahia, a mais antiga publicação sobre indústrias no Nordeste datou de 1966. Trata-se do livro (também publicado na Bahia): O Problema da Industrialização no Brasil, de Luís Henrique Dias Tavares ${ }^{5}$.

A partir da década de 1970, surgiram mais alguns trabalhos sobre a temática, especificamente, na Bahia e em Pernambuco. A produção se acentuou e se disseminou nos outros estados nordestinos no decorrer da década de 1980, porém o crescimento significativo da historiografia sobre o operariado na região só se deu nas décadas de 1990, 2000 e continua crescendo.

Entre os trabalhos produzidos sobre o operariado no/do Nordeste, os estudos que mais repercutiram e influenciaram a produção posterior foram feitos a partir de fins da década de 1970 e tiveram destaque ao longo dos anos 1980, por antropólogas(os) e historiadoras(es) do Museu Nacional do Rio de Janeiro, encabeçadas por José Sérgio Leite Lopes e Maria Rosilene Barbosa Alvim, sobre a Companhia de Tecidos Paulista (CTP), em Pernambuco.

Os estudos apontados no parágrafo anterior - que continuam sendo feitos, articulados aos seus projetos de pesquisa - servem ainda como importante base conceitual e teórica para a compreensão do caráter do operariado nordestino (ou brasileiro como um todo), porque ao mesmo tempo em que fogem do eixo da discussão sobre o latifúndio canavieiro local, o coronelismo, o cangaço ou a seca, levantam problemáticas para a compreensão das particularidades operárias fabris e para o entendimento mais profundo sobre a história e a construção da memória e identidade da região.

A validade dessa premissa está na leitura obrigatória e da constante referência da tese, posteriormente lançada como livro intitulado A Tecelagem do Conflito de Classes na Cidade da Chaminé, de José Sérgio Leite Lopes (1988). Tal relevância a essa obra se dá tanto pelo riquíssimo material documental (oral e escrito) contido nela, como pela inovação analítica a respeito da luta de classes dentro do sistema de "fábrica com vila operária”, em que Lopes utilizou uma metodologia profundamente entrelaçada entre diversos ramos das Ciências Humanas, observando-se a "teatralização do poder", a

\footnotetext{
${ }^{5}$ TAVARES, Luís Henrique Dias. O problema da revolução industrial na Bahia. Salvador, Universidade Federal da Bahia, 1966.
} 
aceitação e resistência à dominação através da percepção de elementos vistos nos símbolos do cotidiano fabril e da vila operária. Assim, por meio da análise sobre um determinado grupo, o autor desenvolveu o estudo de uma forma de dominação específica: o sistema de "fábricas com vila operária".

Outra importante pesquisadora sobre fábricas e vilas operárias é a arquiteta Telma de Barros Correia, que desenvolve estudos sobre essa temática desde o início dos anos 1990, com foco sobre a organização dos espaços fabris no Brasil, utilizados como mecanismos de dominação sobre o operariado. Seu primeiro livro publicado, como resultado da tese de doutoramento, é Pedra: plano e cotidiano operário no sertão (CORREIA, 1998), em que a autora traça um panorama histórico internacional sobre as construções de núcleos fabris; chega à realidade brasileira; e conclui analisando o núcleo fabril de Pedra (atual município Delmiro Gouveia-AL), no sertão alagoano, apresentando os métodos de controle no espaço do núcleo fabril sobre o cotidiano da classe trabalhadora, bem como o simbolismo patriarcal e paternalista da figura de Delmiro Gouveia - proprietário da fábrica - naquele contexto.

Retornando ao estudo de Petersen ${ }^{6}$ referente à produção bibliográfica sobre o operariado no Brasil fora do eixo Rio-São Paulo realizada até o período de dezembro de 2006, a historiadora conseguiu levantar o número de 900 trabalhos, incluindo livros, artigos, teses, dissertações, resumos em anais de congressos, apresentações em eventos científicos, etc. Desses 900, 255 foram sobre a região Nordeste, ou seja, 28,33\%. Dentre esses, apenas 14 foram sobre o operariado alagoano. No âmbito nordestino, Alagoas apareceu com apenas 5,5\%, até o ano de 2006. Em termos de Brasil, fora o eixo Rio-São Paulo, Alagoas teve apenas o total de $1,55 \%$.

Em relação a Alagoas, essa quantidade pode ser considerada irrisória, pois tratase de um estado que teve o número de 12 grandes fábricas têxteis, entre os anos 1930 e 1960, e foi uma das primeiras províncias a fundar a indústria têxtil no país, o que sinaliza que a produção historiográfica esteve, em certa medida, travada pelo acanhado desenvolvimento acadêmico na História e nas Ciências Sociais na região, ao contrário de São Paulo e Rio de Janeiro.

Entretanto, após a finalização do período dos levantamentos bibliográficos de Petersen (dezembro de 2006), observou-se um importante crescimento de pesquisadores

\footnotetext{
${ }^{6}$ Ver PETERSEN, 2009.
} 
e da consequente produção historiográfica em Alagoas sobre a temática do operariado ${ }^{7}$. Em anais de eventos científicos (resumos expandidos ou trabalhos completos) totalizouse o número de 23; em artigos científicos encontram-se 8; três capítulos de livros; seis livros completos publicados; quatro dissertações de mestrado concluídas; quatro teses finalizadas ${ }^{8}$.

\section{A produção historiográfica sobre o operariado em Alagoas: impasses em relação ao "mundo" canavieiro}

A respeito do montante da produção bibliográfica, notou-se que, após as reduzidas 14 publicações sobre o operariado de Alagoas até 2006, tem-se, até então (fins de 2017), 58 trabalhos publicados, ou seja, quatro vezes mais nos últimos 10 anos, sem contar matérias de jornais impressos e produções audiovisuais de emissoras locais tratando, em sua maioria, do abandono da fábrica têxtil de Fernão Velho, principalmente após seu fechamento, em 2010.

Praticamente todas essas últimas publicações foram realizadas por graduados em História pela Universidade Federal de Alagoas (UFAL) ou pela Universidade Estadual de Alagoas (UNEAL) que continuaram suas pesquisas em programas de pós-graduação em outras universidades ou em sua pequena minoria no programa pós-graduação de História da UFAL, criado em $2012^{9}$. Alguns desses pesquisadores já são professores e desempenham trabalhos de pesquisa, o que pode gerar aumento da produção sobre a temática, por meio de possíveis projetos de pesquisa e/ou o estímulo para a orientação de trabalhos acadêmicos.

A despeito desse recente crescimento de estudos sobre o operariado de Alagoas, a maior parte da bibliografia existente, bem como a própria representação da memória alagoana ainda se faz sob o imaginário quase exclusivamente canavieiro. As demais formas de produção e reprodução ficam ainda muitas vezes secundarizadas por conta do

\footnotetext{
${ }^{7}$ Aqui se inseriu também trabalhos sobre o comunismo e o golpe civil-militar de 1964 em Alagoas, devido ao fato de que, nessas temáticas, foram imprescindíveis a presença operária.

${ }^{8}$ Este texto resulta de um recorte sobre a tese de doutorado do autor, defendida em agosto de 2017. Sendo assim, a base de referencial de publicações sobre o operariado em Alagoas se dá até o momento de conclusão da pesquisa.

${ }^{9}$ A implantação tardia de um programa de pós-graduação em um dos cursos mais antigos da Universidade Federal de Alagoas (criado em 1954, com início das atividades em 1961), apresenta-nos uma dificuldade para as pesquisas historiográficas locais. As opções para os graduados que concluíam o curso em História (Licenciatura), na UFAL, era geralmente ingressar na UFPE (Recife) ou migrar para o curso de Sociologia da própria UFAL, fundado em 2003.
} 
predomínio dos estudos sobre as regiões da cana-de-açúcar. Parte desses estudos tenderam a não apresentar as contradições sociais do mundo do trabalho canavieiro. Em muitos casos, observa-se quase uma louvação à "civilização do açúcar", principalmente nos estudos mais antigos ${ }^{10}$.

Segundo Douglas Apratto Tenório (2013, p. 18), dentro do quadro de obras e publicações nas bibliotecas de Alagoas, o número das que se referem à cana-de-açúcar é bem maior do que as que tratam sobre o algodão e a indústria têxtil. Só um adendo: Tenório afirmou que a pouquíssima quantidade de bibliotecas existentes em Alagoas (sete) já é uma indicação do reflexo de sua opção agrária. Vejamos, a seguir, a lista da pesquisa de Tenório:

\section{Quadro 1 - Levantamento bibliográfico sobre a cana-de-açúcar e o algodão em Alagoas}

\begin{tabular}{|l|c|c|}
\hline \multicolumn{1}{|c|}{ Biblioteca } & $\begin{array}{c}\text { Temática da cana ou } \\
\text { açúcar }\end{array}$ & $\begin{array}{c}\text { Temática do algodão ou } \\
\text { indústria têxtil }\end{array}$ \\
\hline $\begin{array}{l}\text { Universidade Federal de } \\
\text { Alagoas (UFAL) }\end{array}$ & $\begin{array}{c}57 \text { livros; } 101 \text { ensaios e } \\
\text { publicações }\end{array}$ & $\begin{array}{c}6 \text { livros; } 10 \text { ensaios e } \\
\text { publicações }\end{array}$ \\
\hline $\begin{array}{l}\text { Centro Universitário } \\
\text { Cesmac }\end{array}$ & 47 livros & 06 livros \\
\hline $\begin{array}{l}\text { Arquivo Público de } \\
\text { Alagoas } \\
\text { (APA) }\end{array}$ & 17 livros & 2 livros \\
\hline $\begin{array}{l}\text { Instituto Histórico e } \\
\text { Geográfico de Alagoas }- \\
\text { IGHAL }\end{array}$ & 43 livros & 07 livros \\
\hline $\begin{array}{l}\text { Academia Alagoana de } \\
\text { Letras }\end{array}$ & 15 livros & 01 livro \\
\hline Sesc Senac & 06 livros & 00 livros \\
\hline $\begin{array}{l}\text { Biblioteca Pública } \\
\text { Estadual }\end{array}$ & 34 livros & 01 livros \\
\hline
\end{tabular}

Fonte: (TENÓRIO, 2013, p. 18).

\footnotetext{
${ }^{10}$ Vertentes contrárias a esta maré de "louvação" canavieira, ou seja, de crítica ao sistema danoso estabelecido pelo poder canavieiro, podem ser encontradas nas pesquisas de estudiosos como Lúcio Vasconcellos de Verçoza, Beatriz Alasia de Heredia, Alice Anabuki Plancherel, Cícero Ferreira de Albuquerque, Araken Alves de Lima, dentre possíveis outros(as) pesquisadores(as) que não cabe aqui adentrar.
} 
Com base no levantamento de Tenório, nota-se o predomínio da visão de mundo açucareira, inclusive, sobre a produção intelectual em Alagoas. A mentalidade da oligarquia canavieira transbordou sobre a autoconstrução da "alagoanidade". Essa concepção não é fortuita, pois dialoga com a mentalidade de dominação agrária existente ainda na atualidade. É, também, no combate contra essa onda do poderio canavieiro-oligárquico que os estudos sobre o operariado alagoano caminham.

Todavia, é importante apontar que aqui não se defende que os espaços fabris têxteis estivessem postos com características sociais mais humanizantes em comparação com os espaços açucareiros, pois as diversas formas de repressão e dominação estiveram muito vivas nas vilas operárias alagoanas. O que se propõe, então, é pensar sobre os interesses da elite canavieira na manutenção de seu poder por meio da construção de uma memória que apaga formas de produção diferentes da açucareira, mesmo que algumas dessas famílias também tenham sido ligadas à indústria têxtil.

Assim, a perspectiva de "louvação canavieira" está presente em um dos mais emblemáticos clássicos alagoanos, O Banguê nas Alagoas (1980), escrito por Manuel Diégues Júnior ${ }^{11}$ (1912-1991), com primeira edição publicada em 1949, em que se coloca Alagoas como espaço exclusivamente agrário-canavieiro: "A história do engenho de Açúcar nas Alagoas quase se confunde com a própria história do hoje Estado [...]. A história de um ditou e condicionou a do outro; acompanha a história do Estado, o desenvolvimento da agricultura da cana e da indústria do açúcar" (DIÉGUES JUNIOR, 1980, p. 23, grifos meus).

Entretanto, o historiador Golbery Lessa discorda da tese de Diégues Júnior, afirmando que

se observarmos apenas as trajetórias da burguesia e dos trabalhadores das fábricas têxteis, já adentramos em um ambiente importante para um melhor entendimento dos descaminhos do ethos capitalista e das relações sociais mercantis em Alagoas, pois essas classes sociais encarnaram a vanguarda do mundo burguês entre o final do século XIX e meados do século XX (LESSA, 2013, p. 103).

O livro, Banguê das Alagoas, pode ser entendido como uma síntese intelectual da defesa das oligarquias canavieiras do estado contra os demais setores, mas não é só isso: foi uma espécie de antecipação da volta da hegemonia da monocultura canavieira (do início dos anos 1960) e de seu predomínio até os dias atuais.

\footnotetext{
${ }^{11}$ É importante perceber que o seu posicionamento está ligado ao fato de este ser membro de família tradicionalmente ligada à cana-de-açúcar em Alagoas.
} 
Mas, se a cultura algodoeira esteva presente em boa parte do território alagoano, entre meados do século XIX e primeira metade do século XX e teve uma importante produção têxtil, que totalizou o número de 12 fábricas instaladas a partir da segunda metade do século XIX e representou importante peso político, econômico, social e cultural para o estado durante quase toda a primeira metade do século $\mathrm{XX}$, por que esse acanhamento historiográfico sobre o algodão?

Para responder à indagação acima, deve-se recorrer a duas premissas. A primeira é a de Marx \& Engels (1977, p. 36), quando afirmaram que "a produção de ideias, de representações, da consciência, está, de início, diretamente entrelaçada com a atividade material e com o intercâmbio material dos homens [...]"; a segunda é a de Walter Benjamin (1987, Tese VII): “todo aquele que, até hoje, obteve a vitória, marcha junto no cortejo de triunfo que conduz os dominantes de hoje [a marcharem] por cima dos que, hoje, jazem, por terra”.

Entre o pressuposto de Marx \& Engels e o de Benjamin, há uma intersecção: o imaginário que se constrói sobre determinada sociedade está umbilicalmente ligado aos interesses da parcela hegemônica da classe dominante que conseguiu destruir os perdedores, isto é, a classe trabalhadora e a parcela minoritária da classe dominante do passado perdem fôlego na construção social da memória. Lembrando que o capital segue a lógica de concorrência inclusive entre a camada social soberana ${ }^{12}$.

Esse raciocínio responde à predominância do setor açucareiro sobre a representação do passado e do presente alagoano, porque, como já dito, a partir dos anos 1950, Alagoas entrou na expansão da agroindústria canavieira nacional e os usineiros saíram vitoriosos frente aos demais setores. A estratégia na mudança de produção em várzea para a produção em tabuleiros foi o pontapé para o predomínio quase exclusivo do canavial nas terras do estado (HEREDIA, 1988).

Dessa forma, entrou novamente a hegemonia das famílias oligárquicas canavieiras, em que tal superioridade implicou no processo de destruição ou desleixo para com qualquer outra forma de atividade concorrente na construção de sua memória e de seu predomínio político na região. Embora existam algumas poucas indústrias, principalmente na cidade de Maceió, o único setor que tem tido representação considerável no estado é o turismo praieiro, sendo dominado pela especulação

\footnotetext{
12 "Em nenhuma sociedade existe um consenso total, não existe simplesmente uma ideologia dominante, existem enfrentamentos ideológicos, contradições entre ideologias, utopia e visões de mundo conflituais, contraditórias" (LOWY, 1987, p. 17).
} 
imobiliária e responsável, em grande parte, pela expulsão das tradicionais famílias de pescadores de suas vilas e povoados no litoral alagoano.

É a partir dessa condição que se pode entender o predomínio da escrita de Alagoas como espaço quase exclusivo do canavial. São válidas, então, as premissas ditas em parágrafos anteriores: as classes dominantes criam mecanismos de dominação da história sobre o espaço em que buscam manter a autoridade, concebendo a sua imagem como natural, benéfica e inevitável.

É preciso lembrar que a construção do passado e da própria formação cultural estão subsumidas à luta de classes do presente, já que o passado não nos aparece em seu sentido revolucionário na imediaticidade, porque as classes dominantes procuram apresentar ideologicamente seus interesses como sendo generalizantes, isto é, os mais adequados e cabíveis para toda a sociedade.

O passado transmitido (quando transmitido) pelos grupos dominantes procura omitir as bases reais do passado, porque ignora os indivíduos que o constrói. A omissão da práxis dos sujeitos e a inserção de uma estrutura ideológica são as bases do pensamento burguês, porque na medida em que avança, busca arrancar da consciência e da inconsciência dos indivíduos a noção de totalidade e de concreticidade.

Na contramão dessa maré reacionária, parte da historiografia alagoana (tal como já afirmado), a partir de meados da década de 2000, acabou trazendo uma investigação academicamente mais rigorosa sobre a história local, na medida em que apresentou a disputa e o predomínio do algodão em certos contextos, da indústria têxtil e da economia comercial portuária, ao menos entre meados do século XIX e a primeira metade do século XX.

\section{A produção fílmica e divulgação de documentações sobre o operariado em Alagoas}

Antes mesmo das primeiras publicações bibliográficas sobre o operariado em Alagoas, houve o importante filme Memória da Vida e do Trabalho (não referenciado por Petersen), sob a direção e produção do renomado cineasta e fotógrafo alagoano Celso Brandão ${ }^{13}$. As suas imagens foram capturadas em 1984 e o seu lançamento

\footnotetext{
${ }^{13}$ Vindo da família Brandão, conhecida pela trajetória intelectual de nomes como Octávio Brandão, Théo Brandão e Teotônio Vilela, a marca de Celso Brandão (Maceió, 1951-) está no vasto registro fílmico e fotográfico de manifestações da cultura popular alagoana em diferentes regiões do estado, com mais de 50 filmes e documentários produzidos. Para acessar algumas de suas produções, ver: <http://projetoandarilha.com/celso-brandao/>.
} 
ocorreu em $1986^{14}$. Com roteiro da arquiteta Regina Coeli e argumento de José Sérgio Leite Lopes e Rosilene Alvim (já aqui mencionados), o filme apresentou uma análise sobre a decadência e abandono das vilas operárias, destacando Fernão Velho ${ }^{15}$, onde a maioria das imagens e depoimentos do operariado da localidade compuseram seu roteiro. Pode-se considerá-lo como um dos mais importantes registros (senão o mais) sobre a condição operária em Alagoas ativa ainda na penúltima década do século XX.

Segundo Maria de Lourdes Lima e Roseane Monteiro Virgínio:

[...] Celso Brandão ao dar imagem e voz às classes subalternas através do seu filme Memória da vida e do trabalho, onde ex-operários testemunham sobre o declínio da fábrica que levou ao processo de modificação e degradação das vilas operárias têxteis de Fernão Velho, Saúde e Rio Largo; ele põe os excluídos como verdadeiros protagonistas. Brandão abre uma janela para vislumbrar a situação dos moradores e denunciar as péssimas condições de vida das pessoas seja no tempo áureo da fábrica ou na época de sua decadência (LIMA e VIRGÍNIO, 2016, p. 37, grifos originais).

Há, também, um vídeo produzido pela Companhia Alagoana de Tecidos, em 1946, situada no município de Rio Largo-AL. Não se trata de uma produção acadêmica, mas de um vídeo de propaganda dos industriais. Foi um trabalho de muita qualidade técnica para a época em que foi realizado, no entanto, está na contramão do vídeo de Celso Brandão, porque louvou "os feitos" dos industriais e apresentou uma imagem encantadora sobre a condição do operariado.

Nele se exaltou a importância dos industriais para o progresso de Alagoas e do Brasil e apresentou, em vários momentos, a suposta preocupação dos capitalistas para com o bem-estar do operariado (ou seria do capital?), demonstrando o atendimento na educação, esporte, médico-hospitalar, lazer, desfiles cívicos e a organização fabril como um todo. Em suma, trata-se de um importante registro histórico para o mundo do trabalho, sobretudo, por demonstrar importantes imagens e exaltar os discursos dos industriais (principalmente sobre a figura de Gustavo Paiva) na época de seu apogeu fabril.

Em tempos recentes, teve a produção dos documentários Trama da Memória, Urdidura do Tempo e O Comendador do Povo: Gustavo Paiva, ambos sob a direção e

\footnotetext{
${ }^{14}$ Importante destacar que esee filme ficou por muito tempo desconhecido por boa parcela da população, pois estava disponível apenas em formato $16 \mathrm{~mm}$. O certo é que o mesmo foi exibido em espaço público em Fernão Velho, em 1999, 2003 e em 2009 (este último pelo projeto Acenda uma Vela). Entretanto, em meados da década de 2000, o filme se popularizou através de cópias de DVDs e, posteriormente, disponibilizado na internet.

${ }^{15}$ Traz imagens também da vila operária de Rio Largo e de Saúde, ambas já em claro estado de abandono no período da filmagem (1984).
} 
coordenação do cineasta alagoano Pedro da Rocha. O primeiro foi do ano de 2011, baseado na obra de Golbery Lessa, e apresentou, como tema central, o questionamento das Alagoas como a "civilização do açúcar", a partir dos depoimentos e pesquisas históricas mais recentes. Golbery Lessa e Sávio de Almeida, em seus depoimentos, enfatizaram a importância do algodão e das indústrias têxteis para o estado. A segunda obra, lançada em 2013, montou a trajetória do comendador Gustavo Paiva, considerado um dos mais emblemáticos industriais das Alagoas, proprietário da Companhia Alagoana de Tecidos, de Rio Largo-AL.

Sobre a divulgação e disponibilização de documentações em Alagoas dos últimos dez anos, houve o importante registro, coordenado por Analice Dantas e Golbery Lessa, e executado em 2007. É a coletânea Trama da Memória, Tessitura do Tempo: registro da memória e da iconografia das famílias de tradição operária têxtil residentes no bairro de Fernão Velho - Maceió/AL. Nele, há dez entrevistas com operários(as) da Fábrica Carmen, com acréscimo de um DVD composto pela digitalização de iconografias de famílias operárias, fotografias do bairro (antigo núcleo fabril), atas sindicais (1953-1964), jornal do PCB/AL A Voz do Povo (1954-1964) e Relatórios Anuais das Fábricas Têxteis de Alagoas.

Uma década após a realização desse registro, pode-se dizer que o mesmo serviu (e ainda serve) como uma das mais importantes fontes documentais para as pesquisas sobre a temática, pois além de trazer material inédito digitalizado e organizado, abre as portas para a necessidade de ampliação de novas pesquisas que possam preencher suas possíveis lacunas.

\section{As gerações de pesquisadores sobre o operariado em Alagoas}

Este artigo divide a produção intelectual sobre o operariado em Alagoas em três diferentes momentos. Os primeiros estudos sobre o operariado no estado nordestino sugiram entre fins dos anos 1980 e início da década de 1990, com Dirceu Lindoso e Luiz Sávio de Almeida, separadamente. A partir de meados da década de 2000, apareceu uma segunda leva de estudos, com Osvaldo Maciel, Fernando Medeiros e Golbery Lessa, também separadamente. A terceira geração, bastante influenciada pela segunda, veio do início dos anos 2010 até o presente. A segunda e a terceira geração continuam a pesquisar e a produzir sobre o operariado de Alagoas ${ }^{16}$.

\footnotetext{
${ }^{16}$ Nota-se que estes estudiosos pesquisaram ou publicaram bem pouco em parceria. Trata-se muito mais de trabalhos em única autoria, embora com contatos entre estes.
} 
Entretanto, um detalhe interessante e preocupante é a ausência de mulheres pesquisadoras em Alagoas sobre o operariado, o que pode ser melhor compreendido em estudos posteriores, porque discutir tal fenômeno escaparia do escopo deste artigo. Uma hipótese que parece plausível condiz com o fato de as mulheres aparecerem muito pouco na história do operariado alagoano e da tímida repercussão dessa temática no meio acadêmico, o que demonstra o caráter patriarcal sobre a construção da imagem do operariado no estado e que vem aos poucos sendo quebrada pelas pesquisas mais recentes ${ }^{17}$.

Voltando à apresentação sobre as gerações de pesquisadores referente ao operariado em Alagoas, aponta-se a primeira geração de estudiosos que tem, em Dirceu $\operatorname{Lindoso}^{18}$, a referência da formação da burguesia comercial maceioense e as especificidades dos espaços de produção fabril na então província, a partir de meados do século XIX. Esse estudo foi escrito em fins da década de 1980, quando Lindoso se tornou membro honorário do Instituto Histórico e Geográfico de Alagoas. Cerca de 20 anos depois, em 2005, essa coletânea de textos foi publicada com o título Interpretação da Província: estudo da cultura alagoana (LINDOSO, 2005), pela EDUFAL.

Outra pesquisa, com mais destaque ao operariado alagoano, foi o conjunto de quatro artigos de Luiz Sávio de Almeida ${ }^{19}$, escritos em 1987, publicados, separadamente, entre os anos de 1989 a 1992, na Revista do Departamento de História da $\mathrm{UFAL}^{20}$, durante o evento Cem Anos de República. O conjunto de artigos na época foi denominado pelo autor como História do Assalariamento em Alagoas. Em 2006, esses artigos foram também publicados em forma de livro impresso também pela EDUFAL, denominado Notas sobre o Poder, Operários e Comunistas em Alagoas (ALMEIDA, 2006).

\footnotetext{
${ }^{17}$ Um dos poucos estudos que apresenta a participação das mulheres operárias é o texto de Sávio de Almeida, Breve reflexão sobre a mulher na indústria têxtil: Alagoas - 1920 (ALMEIDA, 2006, p. 109118). Mais recentemente, há também a penúltima subseção da dissertação de mestrado de Airton Melo (2012), em que o autor denominou como Mulheres de ferro: a greve das tecelãs contra o aumento no número de teares (1962), sobre uma greve ocorrida na Fábrica Carmen de Fernão Velho.

${ }^{18}$ Dirceu Lindoso, nascido em 1932, pode ser considerado um dos maiores historiadores ainda vivo de Alagoas. Imortalizado com sua obra A Utopia Armada (2005), em que fez um grandioso estudo sobre a Guerra dos Cabanos, em Alagoas do século XIX. Em 2011, recebe o título Doutor Honoris Causa pela UFAL, por solicitação e aprovação por unanimidade do Instituto de Ciências Sociais da mesma instituição.

${ }^{19}$ Outro grande nome da historiografia alagoana, Sávio de Almeida, tem um longo trajeto de escritos e militância política em Maceió. Sua produção nos últimos anos está mais voltada à questão indígena e negra em Alagoas.

${ }^{20}$ Os textos da publicação deste período não foram encontrados. É possível que a republicação dessas obras, em meados da década de 2000, tenha influenciado, despertado maior curiosidade e dado estímulo à segunda e terceira levas de produção sobre a temática.
} 
Dentre os dois estudos assinalados anteriormente, o que houve em comum entre eles foi a procura dos embriões da cultura urbana de Alagoas. Sávio Almeida enfatizou o papel das organizações e das greves operárias no estado, entre os anos 1889 e 1932; enquanto Lindoso se preocupou em apresentar a formação cultural e intelectual em diferentes espaços da então província alagoana no século XIX.

Entretanto, nota-se uma lacuna entre essas primeiras publicações e as posteriores, pois, somente em meados da década de 2000 é que retornam as publicações sobre o operariado em Alagoas, mais especificamente após as difusões em livros dos autores da "primeira geração".

É possível que este longo intervalo (cerca de quinze anos) esteja concatenado com alguns fatores, dentre eles: a timidez de pesquisas acadêmicas na área de História/Ciências Sociais no estado; a acanhada divulgação científica dos textos de Lindoso e Almeida; o pouco incentivo estatal-editorial para divulgação e realização de tais pesquisas, relacionadas ao período de sucateamento das universidades nos anos 1990; e, por último, ao distanciamento urbano de Maceió para com as regiões de fábricas e vilas operárias têxteis tradicionais ${ }^{21}$.

Após esse intervalo, surge a segunda geração de estudiosos, na segunda metade da década de 2000, trazendo uma característica academicamente mais rigorosa e voltada à pesquisa em jornais, atas, entrevistas com operários e operárias, além de uma maior aproximação empírica com os espaços fabris, por meio de visitas e pesquisas de campo. Esse maior rigor científico pode ser explicado pelo próprio desenvolvimento de pesquisas acadêmicas no Brasil ao longo da década de 2000, porém a intensificação da procura pela história do operariado local também se fez decorrente da preocupação com a destruição da memória fabril do estado ${ }^{22}$.

Dentre os estudiosos dessa geração, Osvaldo Maciel foi quem apareceu com maior número de publicações sobre a temática operária. Dentre os anos de 2005 a 2011, o pesquisador coordenou um projeto de pesquisa, publicou quatro artigos e lançou dois livros sobre o operariado em Alagoas, em que os focos desses estudos foram a imprensa, o mutualismo, a transição do Império para a República na Província/Estado e

\footnotetext{
${ }^{21}$ Com a ampliação do crescimento urbano de Maceió, principalmente, a partir de meados da década de 2000, espaços antes distantes do grande centro, passam a ser integrados ao núcleo urbano, tal como aconteceu com Fernão Velho, Bom Parto e Rio Largo (cidade vizinha de Maceió).

${ }^{22}$ A última indústria têxtil tradicional do estado, Fábrica Carmen de Fiação e Tecelagem, situada em Fernão Velho, encerrou definitivamente suas atividades em janeiro de 2010, após mais de 150 anos de funcionamento, sendo a mais antiga em atividade no país, até seu fechamento.
} 
a atuação comunista e socialista na região. Sua produção continuou se expandindo pelos anos consecutivos, não só por meio de publicações como em coordenação de projetos de pesquisa e de grupos de trabalhos (GTs) em eventos de cunho científico sobre o mundo do trabalho. Maciel foca sua análise em fontes escritas, principalmente periódicos. Nota-se a possível influência do interesse em compreender a formação da República em Alagoas e a participação da classe trabalhadora naquele processo. $\mathrm{O}$ autor também se desdobra até a década de 1960, com a publicação de seu primeiro livro em que faz um apanhado do levantamento de documentos encontrados, entre 1870 e 1960, sobre a temática operária no estado, publicado em 2007 ${ }^{23}$. Seu último livro (resultado da dissertação de mestrado), de 2009, teve como foco o papel da imprensa na formação da classe trabalhadora local no início da República ${ }^{24}$.

Outro pesquisador dessa geração é Fernando Antônio Mesquita de Medeiros, que desenvolve um projeto de pesquisa, em andamento desde 2009, e teve um livro publicado. Seu foco é a relação entre a Igreja Católica e o anticomunismo em Alagoas ${ }^{25}$. Medeiros é professor da Universidade Federal de Alagoas e continua suas pesquisas a nível de doutorado.

Um historiador que não se pode deixar de fazer referência sobre o período denominado aqui como da "segunda geração" é Geraldo de Majella. Embora não esteja ligado à instituição acadêmica, tem quatro importantes livros publicados sobre a atuação e repressão comunista em Alagoas. Essas obras estão em conexão com a própria militância política do autor, que foi membro do PCB/AL.

Outro da "segunda geração" é o historiador e atual secretário geral do PCB/AL, Golbery Lessa. Embora Lessa não esteja atuando diretamente no meio acadêmico (como professor, por exemplo), ele tem contribuído, de modo significativo, para os estudos sobre o operariado e/ou as esquerdas em Alagoas, porque, além do desenvolvimento de pesquisas, tem tido uma forte aproximação com os mais jovens pesquisadores, contribuindo com fontes e debates, não somente sobre o operariado, mas acerca da sociedade alagoana de uma forma geral.

Boa parte da produção de textos de Golbery Lessa sobre Alagoas pode ser visto

\footnotetext{
${ }^{23}$ MACIEL, Osvaldo Batista Acioly. Operários em movimento: documentos para a história da classe trabalhadora em Alagoas (1870-1960). Maceió: EDUFAL, 2007.

${ }^{24}$ MACIEL, Osvaldo Batista Acioly. Trabalhadores, identidade de classe e socialismo: os gráficos de Maceió (1895-1905). Maceió: EDUFAL, 2009.

25 MEDEIROS, Fernando Antônio Mesquita de. O homo inimicus: Igreja católica, ação social e imaginário anticomunista em Alagoas. Maceió: EDUFAL, 2009.
} 
no blog A Voz do Povo (Alagoas), em que se encontra a diversidade temática já dita. O mais emblemático de seus textos foi publicado no jornal (impresso e virtual), Gazeta de Alagoas, em 2008, intitulado "Para uma História da Indústria Têxtil Alagoana". Esse texto é leitura obrigatória aos estudiosos da temática operária do estado. Mais tarde, em 2013, esse texto foi adaptado e publicado no livro O Ciclo do Algodão e as Vilas Operárias (LESSA; TENÓRIO, 2013).

Dentre os mais jovens pesquisadores, ou seja, os que concluíram mestrado a partir de 2012, aponta-se, neste artigo, como a terceira geração de estudiosos. Estão no número de seis e quase todos continuam pesquisando e publicando sobre o operariado, comunistas e/ou indústria têxtil de Alagoas. Nota-se, entre esses pesquisadores, uma maior ênfase no período democrático brasileiro, entre os anos de 1945 e 1964, embora haja publicações também sobre o século XIX e os anos 1930.

São eles: Rodrigo José da Costa (Doutor em História - UFPE); Gustavo Bruno Costa Neri (Mestre em História - UFAL); Airton de Souza Melo (doutorando em História - UFPE); Anderson Vieira Moura (Doutor em História Social - Unicamp); Marcelo Góes Tavares (Doutor em História - UFPE); e Ivo dos Santos Farias (Doutor em Ciências Sociais - Unesp/Marília).

Até o mestrado, Rodrigo José da Costa teve suas pesquisas dedicadas ao período precedente ao golpe civil-militar de 1964, enfatizando as articulações e mobilizações políticas dos trabalhadores em Maceió, bem como o movimento de repressão policial. Seu trabalho destaca-se pela rigorosa análise histórica sobre os periódicos, uso de documentos como atas de reuniões e documentos do DOPS (Departamento de Ordem Política e Social). Recentemente, está em fase de elaboração de tese de doutorado sobre o PCB, em Alagoas, durante o processo de redemocratização no Brasil (década de 1980 e início de 1990).

Gustavo Neri tem estudado sobre o Integralismo e a perseguição ao comunismo em Alagoas, em meados dos anos 1930, bem como a aliança entre o operariado têxtil e o comunismo. Airton Melo estudou sobre a organização e a repressão sindical entre o operariado têxtil de Maceió no período democrático, com foco na análise documental escrita. Ambos participaram diretamente da pesquisa Trama da Memória, Tessitura do Tempo, aqui já apontada.

Anderson Moura tem desenvolvido pesquisas sobre as notícias em jornais impressos em Alagoas referente ao operariado local, por meio dos periódicos $A$ Voz do Povo, Diário de Alagoas, Gazeta de Alagoas e Jornal de Alagoas; estudos sobre os 
serviços médicos para o operariado; e a relação entre comunistas e trabalhadores urbanos. Todos os seus trabalhos têm como foco o período democrático brasileiro (1946-1964) e traz rigorosa e inovadora análise sobre documentação escrita de fôlego.

Marcelo Tavares, atualmente professor de História pela Universidade Estadual de Alagoas, entrou em contato com o tema em período relativamente recente, isto é, somente a partir de sua inserção no doutorado em História, pela UFPE, onde desenvolveu sua tese de doutoramento sobre o operariado de Fernão Velho. Em fins de 2017, organizou e publicou pela Editora da Universidade Federal de Alagoas, o livro: Nas travessias do tempo: histórias de protagonismos, resistências e lutas políticas, em parceria com pesquisadores de Alagoas.

Por fim, nesta "terceira geração" encontra-se o autor que aqui escreve, Ivo dos Santos Farias, que desenvolveu pesquisa sobre o operariado de Fernão Velho desde a graduação em História (UFAL) e concluiu tese de doutoramento em Ciências Sociais (Unesp-Marília). É membro do grupo estudado, por ter nascido e ser criado na vila operária, sendo filho de líder sindical. No início de 2015, publicou o livro (resultante da dissertação de mestrado em Sociologia pela UFAL): Nossa casa é do patrão: dominação e resistência operária em Fernão Velho, em que analisou os mecanismos de dominação pelos indústrias, bem como as formas de resistência do operariado. Sua tese de doutoramento tratou do processo de desmonte fabril e da necessidade de recuperação da memória para a classe trabalhadora.

\section{Considerações finais}

Foi apresentado, muito resumidamente, o que há, até então, disponível para pesquisas sobre a historiografia do operariado em Alagoas, em seus diferentes momentos, bem como uma discussão sobre a importância dessa construção para se rever a perspectiva a respeito da identidade social de Alagoas.

Como se pôde perceber ao longo deste artigo, os estudos sobre o operariado em Alagoas cresceram de modo significativo ao longo da última década, o que pode contribuir na elaboração de novas problemáticas para repensar a memória e a história, não somente regional, mas também em âmbito nacional, na medida em que esses estudos apontam a existência da articulação operária fabril, tanto do ponto de vista sindical e partidária quanto nos aspectos cotidianos, trazendo experiências pouco exploradas na história de Alagoas, porque não dizer do Nordeste. 
Entende-se aqui que esse crescimento está interligado com a necessidade urgente de reconstrução da memória fabril no estado, tendo em vista o abandono de seus espaços de produção têxtil, o que instiga os historiadores a investigar sobre o passado que está sendo apagado e necessita ser recuperado para não se cair no conformismo de aceitação de apenas uma perspectiva histórica, a qual muitas vezes pode levar a compreensões errôneas a respeito de sua formação social.

Portanto, trazer à tona a existência de um operariado fabril que se formou junto ao processo de modernização (conservadora) de Alagoas, que, além de estar conectado com as discussões políticas, criou elementos próprios de diálogos que se pode identificar como uma cultura popular operária, visualizadas por meio da musicalidade, da criação artística e da festividade como um todo, que necessitaria de um outro trabalho para melhor se apresentar. 


\section{REFERÊNCIAS}

ALMEIDA, Luiz Sávio de. Notas sobre o poder, operários e comunistas em Alagoas. Maceió: EDUFAL, 2006.

BENJAMIN, Walter. Sobre o conceito de história. In: BENJAMIN, Walter. Magia e técnica, arte e política: ensaios sobre literatura e história da cultura. v. 1. São Paulo: Brasiliense, 1987b. p. 222-232.

O COMENDADOR do povo. Direção: Pedro da Rocha. Maceió, 2013. 1 DVD (54min). son., color.

COMPANHIA Alagoana de Fiação e Tecidos. Produção de Willian Gericke. Rio Largo: Meridional Filmes, 1946.

CORREIA, Telma de Barros. Pedra: plano e cotidiano operário no sertão. Campinas: Papirus, 1998.

COSTA, Rodrigo José da. O golpe civil-militar em Alagoas: o governo Luiz Cavalcante e as lutas sociais (1961-1964). 2013. 159f. Dissertação (Mestrado em História) - Centro de Filosofia, Letras e Humanas, Universidade Federal de Pernambuco, Recife, 2013.

DIEGUES JUNIOR, Manuel. O banguê nas Alagoas: traços da influência do sistema econômico do engenho no açúcar na vida e na cultura regional. 2.ed. Maceió: EDUFAL, 1980 .

FARIAS, Ivo dos Santos. Nossa casa é do patrão: dominação e resistência operária no núcleo fabril de Fernão Velho (Maceió-AL). Curitiba: Appris, 2014.

HARDMAN, Franciso Foot; LEONARDO, Victor. História da indústria e do trabalho no Brasil: das origens até os anos vinte. São Paulo: Global Ed., 1982.

HEREDIA, Beatriz Alaisa de. Formas de dominação e espaço social: a modernização da agroindústria canavieira em Alagoas. São Paulo: Marco Zero; Brasília, DF: MTC/CNPq, 1988.

LEITE LOPES, José Sérgio. A tecelagem dos conflitos de classes na cidade da chaminé. São Paulo: Editora Marco Zero; Brasília: Editora da Universidade de Brasília, 1988 .

LESSA, Golbery; TENÓRIO, Douglas Apratto. O ciclo do algodão e as vilas operárias. Maceió: Sebrae, 2013.

LIMA, Maria de Lourdes; VIRGINIO, Roseane Monteiro. Celso Brandão: um intermediário cultural. Revista Extensão em Debate, $3^{\mathbf{a}}$ Ed. Especial de Cinema, Maceió, 2016. p. 31-39.

LINDOSO, Dirceu. Interpretação da província: estudo da cultura alagoana. 2.ed. Maceió: EDUFAL, 2005. 
LOWY, Michael. As aventuras de Karl Marx contra o barão de Münchhausen: marxismo e positivismo na Sociologia do Conhecimento. 2.ed. São Paulo: Busca Vida, 1987.

MARX, Karl; ENGELS, Friederich. A ideologia alemã. I - Feuerbach. São Paulo: Grijalbo, 1977.

MEMÓRIA da vida e do trabalho. Direção e produção de Celso Brandão. Argumento e texto: José Sérgio Leite Lopes e Rosilene Alvim. Roteiro: Regina Coeli. Maceió: Estrela do Norte,1986. 1 DVD (20 min). son., color.

PETERSEN, Sílvia Regina Ferraz. Levantamento da produção bibliográfica e de outros resultados de investigação sobre a história operária e o trabalho fora do eixo Rio-São Paulo. Cadernos AEL, Campinas, UNICAMP, v.14, n. 26, $1^{\circ}$ sem. 2009.

POLLAK, Michael. Memória e identidade social. Estudos históricos, Rio de Janeiro, v. 5, n. 10, 1992, p. 200-212.

PORTELLI, Alessandro. O massacre de civitella vai di chiana. In: FERREIRA, Marieta de Moraes; AMADO, Janaína. Usos \& abusos da história oral. Fundação Getúlio Vargas, 1998. p. 103-130.

TENÓRIO, Douglas Apratto. A tragédia do populismo: o impeachment de Muniz Falcão. 2.ed. Maceió: EDUFAL, 2007.

TRAMA da Memória, urdidura do tempo. Produção de Pedro da Rocha. Maceió, 2011.1 DVD (30 min), son., color. 